\title{
Forensic Ballistic Studies of 9mm Jacketed Pistol Bullets on Passage through Iron Sheets of Different Thicknesses
}

\author{
Kaur S $^{*}$, Modi JK ${ }^{2}$ and Murthy SS ${ }^{3}$ \\ ${ }^{1}$ Forensic Professional (Ballistics), Central Forensic Science Laboratory, Ramanthapur, \\ Hyderabad, India
}

${ }^{2}$ Senior Faculty (Ballistics), LNJN National Institute of Criminology \& Forensic Science, New Delhi, India

${ }^{3}$ Assistant Director (Ballistics), Central Forensic Science Laboratory, Ramanthapur, Hyderabad, India

*Corresponding author: Sahib Kaur, Forensic Professional (Ballistics), Central Forensic Science Laboratory, Ministry of Home Affairs, Govt. of India, Hyderabad, India, Tel: +91-9654542459; Email: kaursahib12@gmail.com

\section{Abstract}

In criminal investigation, one often comes across cases involving the passage of different types of bullets in objects made of or fitted with metallic sheets of varying thicknesses. In this paper, the authors have studied the interaction of $9 \mathrm{~mm}$ bullets with iron sheets of varying thicknesses with gauge numbers varying from 30 to 14 . The authors have observed that (i) the nose of the bullets becomes flattened, (ii) in sheet of gauge number 14 of thickness $2 \mathrm{~mm}$, the lead core and jacket may get separated, or the bullet may turn into a disc, (iii) the diameter of the bullet hole depends upon the energy lost by bullet and hence in some thicker sheets, the diameter of hole may become larger than the calibre of bullet, (iv) there is formation of plug which may also penetrate in human body, (v) there is formation of some tiny fragments of iron which may produce slight contusions on human body around the gunshot hole, (vi) the bullets do not lose appreciable weight while passing through sheet, (vii)striations on bullets that had passed through the sheets of gauge numbers 30 to 16 and on the jacket that had been separated from the core while passing through sheet of gauge number 14 are maintained, thereby, enabling the evidence bullets to be linked with a suspected firearm, and (viii) the bullets are lethal even after their passage through sheets.

Keywords: Forensic Ballistics; Experimental Firings; 9mm Jacketed Pistol Bullets; Iron Sheets; Gauge Number; GunShot Hole; Bullet Deformation; Plug Formation

\section{Introduction}

In crime involving firearms, a bullet may impact on various objects like almirah, filing cabinet, coolers, refrigerators, washing machines, buses, cars, motorcycles, etc. which are made of or fitted with thin iron sheets and hence these objects may become objects of 


\section{International Journal of Forensic Sciences}

criminal investigation. In such cases, an investigator is often interested in knowing about the following points:

- Type of bullet that had caused the hole, whether it is jacketed or non-jacketed or soft-point bullet.

- What is the calibre of the bullet from dimensions of hole in target?

- Which is the entrance side and which is the exit side?

- What was the range of firing?

- Whether the bullet recovered from scene of crime, after it has passed through the sheet, can be linked with suspected firearm? In other words, what is the possibility that the striations on bullet left by the individual characteristics present in firearm are maintained on the bullet or get damaged after its passage through the sheet?

- What is the lethality of bullet after its passage?

- What is the mode of defeat of target? Is there any plug formation?

- To what extent, the bullet gets deformed? Is there any loss in weight of bullet, etc.
These effects depend upon firearm-cartridge-target combination. In other words, these effects depend on mass, calibre, shape of nose, striking velocity and angle of impact of bullet and the nature and thickness of target. In order to gain some knowledge about above mentioned points, the authors have conducted experimental firings of $9 \mathrm{~mm}$ jacketed bullets through iron sheets of different gauges with gauge numbers varying from 30 to 14 , as some of the household objects or vehicles may be fitted with sheets of such gauge numbers. The bullets were fired through a $9 \mathrm{~mm}$ carbine held perpendicular to the target sheets. These firings have been analysed and the results are presented in this paper.

\section{Materials and Methods}

In this study, the authors fired $9 \mathrm{~mm}$ jacketed bullet through iron sheets of different thicknesses varying from gauge number 30 to gauge number 14 . Firings were conducted by $9 \mathrm{~mm}$ carbine manufactured by Indian Ordnance Factories. Each sheet was of size $30 \mathrm{~cm} \times 30 \mathrm{~cm}$, with thickness varying according to gauge number as shown in Table 1.

\begin{tabular}{|c|c|c|c|}
\hline S. No & $\begin{array}{c}\text { Gauge number } \\
\text { of iron sheet }\end{array}$ & $\begin{array}{c}\text { Thickness of iron sheet } \\
\text { (in mm) }\end{array}$ & $\begin{array}{c}\text { Thickness of iron } \\
\text { (in inches) }\end{array}$ \\
\hline $\mathbf{1 .}$ & 30 & 0.29 & 0.011 \\
\hline $\mathbf{2 .}$ & 28 & 0.38 & 0.015 \\
\hline $\mathbf{3 .}$ & 26 & 0.55 & 0.022 \\
\hline $\mathbf{4 .}$ & 24 & 0.7 & 0.027 \\
\hline $\mathbf{5 .}$ & 22 & 0.8 & 0.031 \\
\hline $\mathbf{6 .}$ & 20 & 1.05 & 0.041 \\
\hline $\mathbf{7 .}$ & 18 & 1.25 & 0.05 \\
\hline $\mathbf{8 .}$ & 16 & 1.5 & 0.06 \\
\hline $\mathbf{9}$ & 14 & 2.0 & 0.079 \\
\hline
\end{tabular}

Table 1: Showing thickness of iron sheets of different gauge numbers in millimetres $(\mathrm{mm})$ and in inches.

The number of shots fired through sheet of each gauge varied from 8 to 10 .

Ideally, the velocity of bullets prior to their passage through the sheet and after passage through the sheet should be ascertained to find loss in velocity suffered by bullets in passing through sheets of various gauges. But, there was limitation of having only one velocity measuring system. Thus this system was used to determine velocity of bullet after its passage through the sheet. However, to estimate the velocity of bullet prior to its passage through the sheet, ten $9 \mathrm{~mm}$ cartridges taken from the same box were fired and their velocities were determined. The mid-point of the screens of velocity measuring system was at a distance of about 2.3 meters from the muzzle of carbine. The average of these determined velocities was taken as instrumental velocity of bullets at a distance of about 2.3meters from the muzzle. The muzzle-velocity of bullets was taken as approximately equal to this instrumental velocity. The make of ammunition used was also of Indian Ordnance Factories.

The iron sheets were firmly fixed in front of velocity measuring system. Behind the system, there was a target box of 4 feet $\times 4$ feet $\times 2$ feet dimensions filled with cotton so as to arrest the bullets. At the front of this target box, a stack of 5 cardboard sheets with total thickness of 7-8 


\section{International Journal of Forensic Sciences}

$\mathrm{mm}$ was fitted. The distance between the iron sheet and first screen of velocity measuring system was $50 \mathrm{~cm}$. The distance of recovery box from rear screen of velocity measuring system was about $50 \mathrm{~cm}$. The distance between screens was about 1.6 meters. The firings were conducted with muzzle at a distance of one meter from the sheet. Thus the distance between muzzle and mid-point between the screens was 2.3 meters. Firings were conducted with this setup with iron sheets and the remaining velocities were determined at a distance of 1.3 meters after exit from the sheet. Through sheet of each gauge, 7-8 rounds were fired and the average of bullet velocities was calculated which was taken as remaining velocity of the bullet after its passage through sheet of that particular thickness. Each fired bullet was recovered from bullet recovery box and was examined physically, chemically and microscopically.

Before discussing the results of firings, the impact of jacketed bullets on iron sheets is discussed below:

\section{Impact of Jacketed Bullets on Iron Sheets}

When $9 \mathrm{~mm}$ jacketed bullet makes impact on iron sheet, at point of impact, a two-way action occurs during the collision, transfer of energy takes place and stress waves are produced both in the bullet and target. The stresses produced in the bullet deform its nose. The sheet bends in the direction of bullet. When the stresses produced exceed the ultimate tensile strength of the metal plate, it ruptures and a hole is created. Here the margins of the metal sheet at the hole are directed towards the direction of motion of bullet and are very irregular i.e. the margins are everted. This is called rearward petalling. Also, some small iron particles/chips are projected in the direction of firing. Sometimes, depending upon the thickness of sheet, the stresses induced are more than the elastic limit of sheet but less than the tensile strength, causing bending of sheet in the direction of force without causing any hole in the sheet. Sometimes, because of impact of blunt-nosed $9 \mathrm{~mm}$ bullet, the sheet bends and there is formation of plug. For the formation of plug, the concept of adiabatic shearing has been developed [1]. On initial impact, a local ring of intense shear is generated, locally intense heat is generated. Since the time of impact is of the order of micro-seconds, the material of the target tends to yield and a plug is formed and breaks free.
As the thickness of iron sheet increases, the resistance offered by the sheet to the passage of bullet increases. Bullet imparts more kinetic energy to the sheet. The metal of sheet also takes up energy and moves in lateral direction causing the hole to expand, as explained below in II. The deformation of bullet varies from flattening of its nose to its fragmentation with increase in the sheet thickness.

\section{Observations and Analysis}

As mentioned above, $7-8$ rounds of $9 \times 19 \mathrm{~mm}$ cartridges were fired from a carbine through iron sheets of gauge number $30,28,26,24,22,20,18,16$ and 14 . The initial instrumental velocity at a distance of 2.3 meters from muzzle was taken as average of 10 firings and it is $1008 \mathrm{ft} / \mathrm{sec}$. The average initial weight of $9 \mathrm{~mm}$ pistol bullet was determined by opening number of $9 \mathrm{~mm}$ rounds and weighing their bullets. Average of these bullet weights has been taken as the standard value of weight of $9 \mathrm{~mm}$ bullet. This value of bullet weight was determined to be 7.490grams. The experimental results of firings of $9 \mathrm{~mm}$ bullets through iron sheets of various gauges and their analysis are as follows:

\section{Nitrite Particles around the Holes}

It was suspected that some unburnt or partially burnt propellant particles may produce some marks on the metal sheets and then may fall on ground. So, the area around the holes caused by bullets was tested chemically with Whatman filter paper moistened with 1:1 solution of sulphanilic acid and $\alpha$ - naphthylamine [2]. No marks were found. Since the firings were conducted from muzzletarget distance of one meter, it is likely that these particles may not reach the target, as the tattooing with carbines generally occurs upto $30 \mathrm{~cm}$ to $60 \mathrm{~cm}$.

\section{Diameter of Gunshot Hole in Sheets of Different Thicknesses}

When the $9 \mathrm{~mm}$ bullet was fired through sheets of various gauges, the resulting hole diameters are given below in Table 2 and are also shown in Graph 1. This table shows that the diameter of the hole increases when the thickness of sheet increases from gauge number 30 to 28 . It remains constant in sheets of gauges 28 to 22 and again increases from gauge 20 to 16 . In other words, as the thickness of the sheet increases, the diameter of the hole initially increases, then remains practically constant and then increases again. 


\section{International Journal of Forensic Sciences}

\begin{tabular}{|c|c|c|c|}
\hline S. No & Gauge number of Iron sheet & $\begin{array}{c}\text { Thickness of Iron sheet } \\
\text { (in mm) }\end{array}$ & $\begin{array}{c}\text { Average Diameter of Gunshot hole } \\
\text { (in mm) }\end{array}$ \\
\hline $\mathbf{1}$ & 30 & 0.29 & 8.02 \\
\hline $\mathbf{2}$ & 28 & 0.38 & 8.9 \\
\hline $\mathbf{3}$ & 26 & 0.55 & 8.94 \\
\hline $\mathbf{4}$ & 24 & 0.7 & 8.94 \\
\hline $\mathbf{5}$ & 22 & 0.8 & 8.92 \\
\hline $\mathbf{6}$ & 20 & 1.05 & 9.2 \\
\hline $\mathbf{7}$ & 18 & 1.25 & 9.97 \\
\hline $\mathbf{8}$ & 16 & 1.5 & 11.45 \\
\hline $\mathbf{9}$ & 14 & 2 & 10.68 \\
\hline
\end{tabular}

Table 2: Showing the diameters of gun-shot holes caused by passage of $9 \mathrm{~mm}$ bullet through sheets of different gauges.

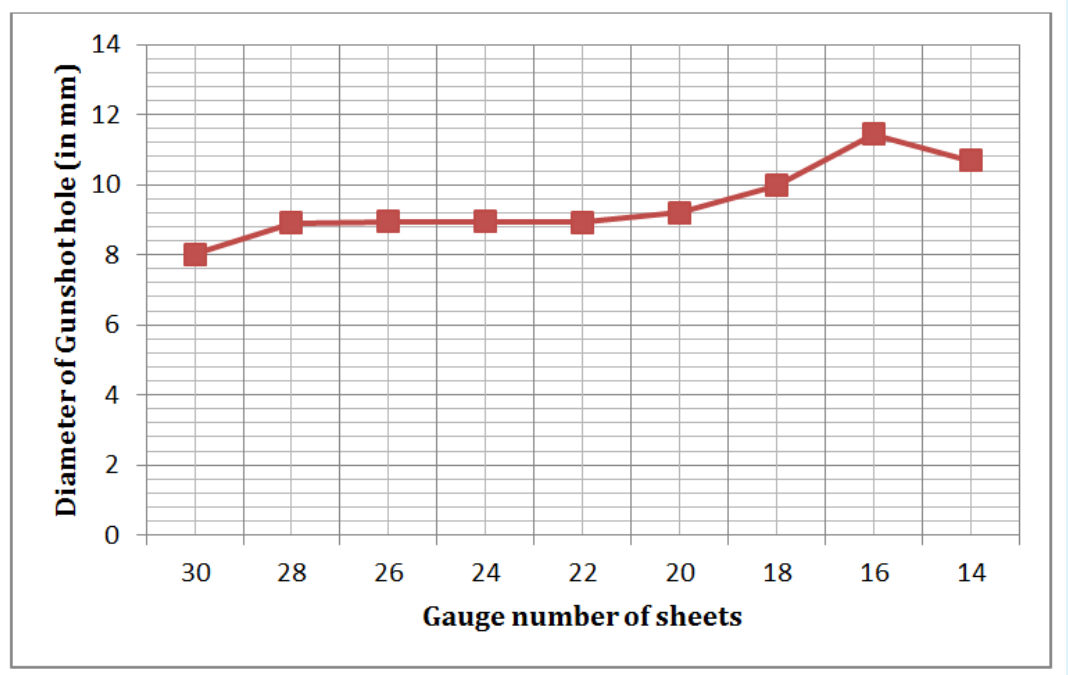

Graph 1: Showing variation in diameters of holes with gauge number of sheets.

As the thickness increases, the diameter of the hole increases. This is firstly due to the deformation of bullet nose, and secondly, as the thickness increases, the bullet loses more and more energy and the metal which is elastic in nature takes up part of this energy and starts moving in lateral direction and returns to the original position after the bullet had passed through the sheet. In thin sheets, say of gauge number $30(=0.29 \mathrm{~mm})$, transfer of this energy making the metal to move in lateral direction is within the elastic limit of iron and the sheet returns to its original position making the entrance hole smaller than the calibre of the bullet. Now when the thickness increases, say for gauge numbers 28 $(=0.38 \mathrm{~mm}), 26(=0.55 \mathrm{~mm}), 24(=0.7 \mathrm{~mm}), 22(=0.8 \mathrm{~mm})$, the transfer of energy used up for lateral movement of metal is within the elastic limit and after the sheet had moved back to its original position, the diameter of the hole is nearly equal to the calibre of the bullet. But when thickness of sheet becomes about $1 \mathrm{~mm}$, say for gauge number $20(=1.05 \mathrm{~mm})$, gauge number $18(=1.25 \mathrm{~mm})$ and $16(=1.5 \mathrm{~mm})$, the transfer of energy for lateral movement of metal is beyond its elastic limit, metal of sheet acquires permanent set [3] and the diameter of hole becomes larger than the calibre of bullet. Farrar and Leeming [5] in their book entitled Military Ballistics have mentioned that, "numerous theoretical models have been developed in attempts to predict the perforating ability of a projectile without conducting experimental firings.

In most of the theoretical developments, the volume of hole produced by the impacting projectile is assumed to 


\section{International Journal of Forensic Sciences}

be proportional to the kinetic energy lost by projectile when it perforates the plate."

From our studies, we conclude that one of the factors responsible for making the diameter of hole larger than calibre of bullet is the kinetic energy lost by the bullet while passing through the sheet. Sheets of gauge number $14(=2.0 \mathrm{~mm})$, presented so much resistance to the passage of bullet that sometimes the bullets failed to pass through the sheet, sometimes lead core and jacket got separated and lead core deformed and turned into a disc. Sometimes lead core rebounded. The bullet hole was larger than the calibre of bullet.
As in the case of gun-shot wounds, it is not possible to determine the calibre of bullet from the diameter of hole in sheets.

\section{Bullet Deformation during Its Passage in Sheets of Different Thicknesses}

From the above, it is found that the diameter of bullet hole in iron sheets of different thicknesses depends upon the kinetic energy lost by the bullet. This depends upon the thickness of the sheet and deformation of bullets. The deformation suffered by bullets on passing through sheets of different gauges is shown in Figure 1.

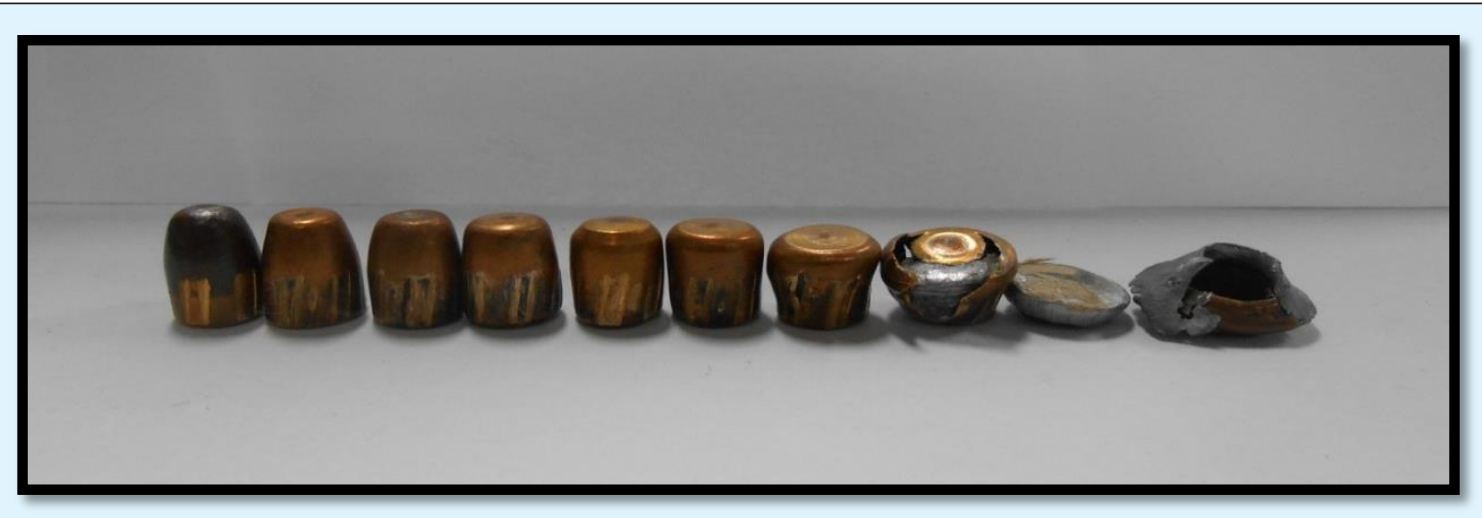

Figure 1: Showing extent of deformation in $9 \mathrm{~mm}$ jacketed bullets on passage through iron sheets of gauges $30,28,26,24,22,20,18,16,14$ respectively(from left to right). The bullet after passing through $2 \mathrm{~mm}$ thick iron sheet (14 gauge) got separated between core (shaped as a disc) and jacket (along with some part of lead).

The following Table 3 gives the average diameter of bullet at its nose, at its base and length after their passage

through iron sheets of different gauges.

\begin{tabular}{|c|c|c|c|c|c|}
\hline S. No. & $\begin{array}{c}\text { Gauge number } \\
\text { of Iron sheet }\end{array}$ & $\begin{array}{c}\text { Thickness of Iron } \\
\text { sheet (in mm) }\end{array}$ & $\begin{array}{c}\text { Average diameter of the } \\
\text { bullet at nose (in mm) }\end{array}$ & $\begin{array}{c}\text { Average Diameter of the } \\
\text { bullet at base (in mm) }\end{array}$ & $\begin{array}{c}\text { Average Length of } \\
\text { the bullet (in mm) }\end{array}$ \\
\hline $\mathbf{1}$ & 30 & 0.29 & 6.68 & 9.04 & 14.24 \\
\hline $\mathbf{2}$ & 28 & 0.38 & 6.73 & 8.95 & 14.1 \\
\hline $\mathbf{3}$ & 26 & 0.55 & 7.31 & 9.04 & 13.72 \\
\hline $\mathbf{4}$ & 24 & 0.7 & 8.13 & 9.01 & 13.11 \\
\hline $\mathbf{5}$ & 22 & 0.8 & 8.08 & 8.93 & 13.01 \\
\hline $\mathbf{6}$ & 20 & 1.05 & 8.9 & 8.918 & 12.54 \\
\hline $\mathbf{7}$ & 18 & 1.25 & 10.39 & 8.973 & 11.71 \\
\hline $\mathbf{8}$ & 16 & 1.5 & 12.14 & 9.04 & 11.16 \\
\hline $\mathbf{9}$ & 14 & 2 & \multicolumn{2}{|c|}{ "Diameter of Disc $=11.59 \mathrm{~mm}$} & 5.87 \\
\hline
\end{tabular}

\#In iron sheet of gauge14, the deformation of the bullet was such that while passing through the sheet, core got separated from the jacket and became a circular shaped disc.

Table 3: Showing the average dimensions of bullets after their passage through sheets of different gauges. 


\section{International Journal of Forensic Sciences}

Following graphs show how the nose diameter, base through sheets of different gauges (Graph 2-4) diameter and length of the bullets vary as they passed

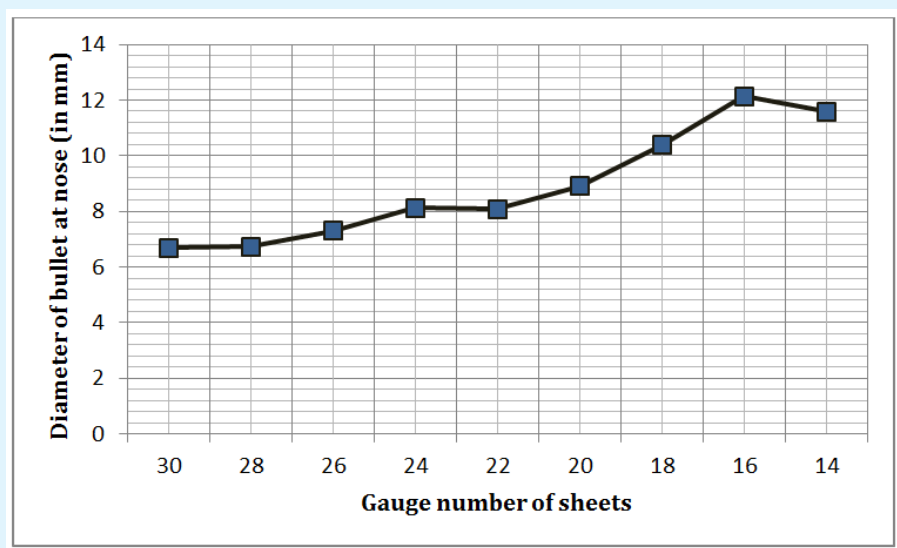

Graph 2: Showing variation in diameter of bullet nose with gauge number of sheets.

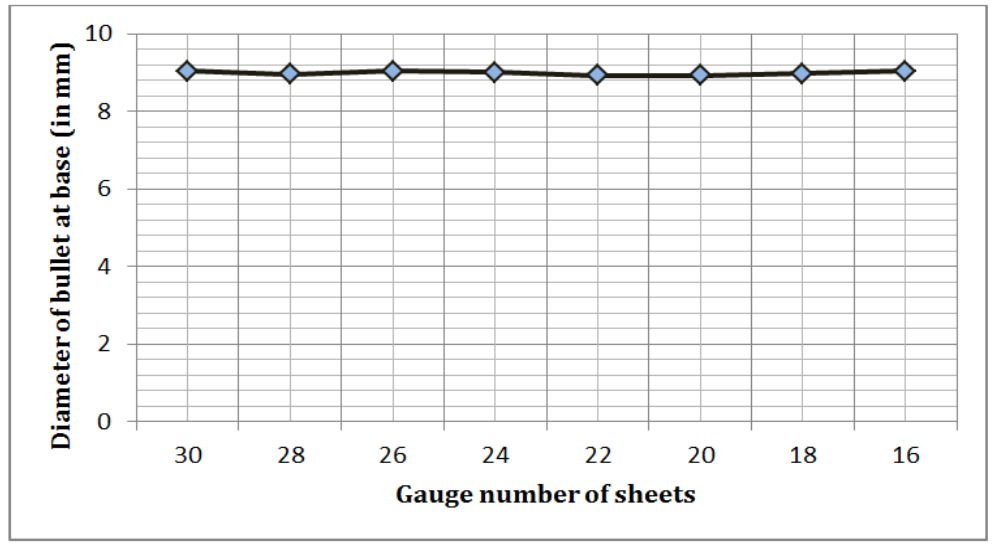

Graph 3: Showing diameter of base of bullets as a function of their passage through iron sheets of different gauge numbers.

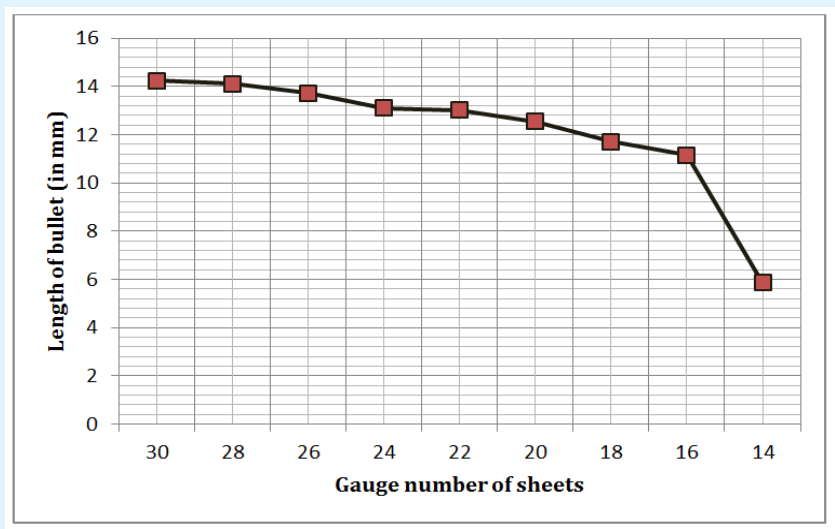

Graph 4: Showing variation in bullet length with gauge number of sheets. 


\section{International Journal of Forensic Sciences}

These graphs show that as the bullet passes through iron sheets of increasing thickness, the diameter of nose increases. The bullet nose begins to flatten when it passed through sheet of gauge number 28 and onwards. When bullet was fired through sheet of gauge number 18, it was observed that cracks had developed in jacket of bullet. The jacket ruptured when it passed through sheet of gauge number 16 . When the bullet was fired in sheet of gauge number 14, the jacket and core had separated, the jacket along with some part of lead flew towards the shooter and the core turned into a disc of diameter $11.59 \mathrm{~mm}$. These graphs also show that diameter of bullet at base remains unchanged.

The length of bullet, however, gradually decreases upto sheet of gauge number 16. In sheet of gauge 14, some deformed lead cores having average length (or say thickness) of $5.87 \mathrm{~mm}$ passed through the sheet and were recovered from the recovery box.

\section{Motion of Plug}

As mentioned earlier, when $9 \mathrm{~mm}$ bullet passed through iron sheets, there was formation of plug, that is, a circular piece of iron sheet got cut by the impact of bullet and moved ahead of the bullet. This plug may remain attached to the bullet for some distance and then gets separated from bullet. This plug is unable to overcome air-resistance, soon slows down and falls on ground. This plug can also cause injury. For example, in one case a single round was fired, but there were two injuries on back of the neck of victim. Defence counsel alleged firing of two shots. One injury was circular and the other, below this circular injury, was of triangular shape. From the circular wound, a bullet was recovered and from the triangular wound, a triangular piece of iron was recovered. The scene of crime was visited where an iron chisel was found. On the sharp cutting edge of this chisel, a triangular defect was found. The triangular piece of iron taken out of body of victim could be physically fitted into this defect. This showed that the bullet had first struck the chisel, took out the triangular plug along with it, both got separated just before entering the neck and produced separate wounds on the neck of the victim. That's how it was proved to be a case of one shot.

\section{Motion of Plug in Relation to Motion of Bullet through Sheets}

As a result of its passage through sheets of different thicknesses, the velocities of $9 \mathrm{~mm}$ bullet differs. Thin sheets produce less resistance to its passage than thick sheets. So, a bullet after its passage through a thin sheet has more velocity than that of the one which had passed through thicker sheets. Moreover, in the case of thin sheets, the plugs are lighter than in case of thick sheets. Thus, the plugs have different thicknesses and different velocities. The air-resistance acting on the plug depends upon $\rho v^{2} A^{2}$, where $\rho$ is the density of air, $v$ is the velocity of plug and $A$ is the area of plug acted upon by air. The plug, being lighter, experiences more retardation than the bullet, it soon slows down, gets separated from the bullet and falls down.

The following Figure 2 shows the forces acting on a plug while moving in air. Here, ' $m$ ' is the mass of plug and ' $a$ ' is the retardation.

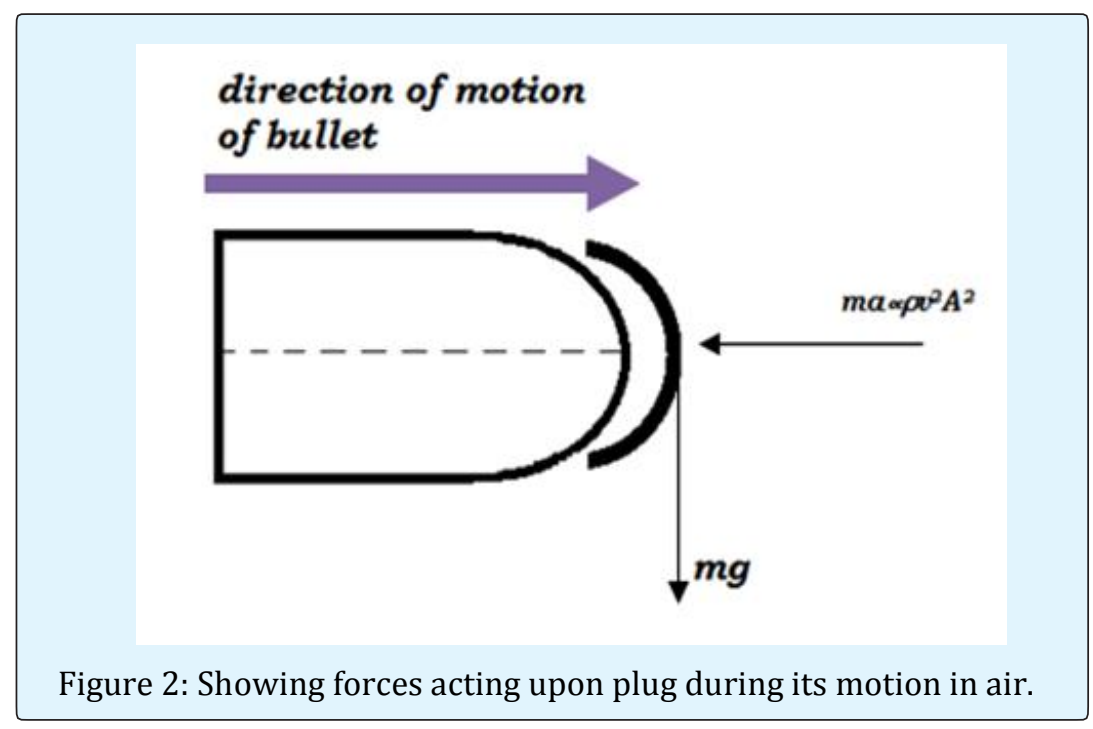




\section{International Journal of Forensic Sciences}

In the experiment conducted by authors, the following Table 4 gives the positions of plug when the bullets passed through sheets of different thicknesses:

\begin{tabular}{|c|l|}
\hline Gauge Number of Iron sheet & \multicolumn{1}{|c|}{ Position of Plug } \\
\hline $\mathbf{3 0}$ & Attached to the bullet nose, both found intact together inside the recovery box. \\
\hline $\mathbf{2 8}$ & Attached to the bullet nose, both found intact together inside the recovery box. \\
\hline $\mathbf{2 6}$ & Plug and bullet separated and both entered in the recovery box. \\
\hline $\mathbf{2 4}$ & Some plugs entered the bullet recovery box and some fell outside the box. \\
\hline $\mathbf{2 2}$ & Some plugs entered the recovery box and some fell outside the box. \\
\hline $\mathbf{2 0}$ & All the plugs penetrated the stack of cardboards upto a depth of about 6-7mm. \\
\hline $\mathbf{1 8}$ & All plugs penetrated the stack of cardboards upto a depth of about 6mm. \\
\hline $\mathbf{1 6}$ & $\begin{array}{l}\text { These plugs were thicker as compared to plugs formed in sheets given above. These } \\
\text { penetrated the stack of cardboards upto a distance of 4-5mm. }\end{array}$ \\
\hline $\mathbf{1 4}$ & $\begin{array}{l}\text { Heavier plugs formed. These plugs fell on the ground soon after their detachment from } \\
\text { the sheet. }\end{array}$ \\
\hline
\end{tabular}

Table 4: Giving the positions of plug when $9 \mathrm{~mm}$ bullets passed through sheets of different gauge numbers.

As mentioned in the above table, during the experiments it was found that the plugs formed in sheets of gauge number 30 and 28 were found sticking to the nose of bullet. Normally, when the target is thin, the piece of target sticks to the bullet's nose. As the thickness increases, the plug and bullet got separated. For example, in sheets of gauge number $26,24,22,20,18$ and 16 , the plugs had separated from the bullets. While the bullets have entered deep in the bullet recovery box, the plug either entered the recovery box and failed to go deep inside the box or fell down outside the box. In case of sheet of gauge number 14, the plugs were thick and heavy and soon fell on ground. This behaviour of plug depends upon its mass, velocity, shape, area presented to the air, etc.

\section{Effect on Striations on Bullets After Their Passage Through Iron Sheets}

All the bullets which had passed through iron sheets of gauge number 30 to 16 , that is, through sheets of thickness varying from $0.29 \mathrm{~mm}$ to $1.5 \mathrm{~mm}$ were compared with test bullets fired initially straight into the bullet recovery box, using comparison microscope. It was found that striations on all the bullets which have passed through the sheets matched with striations on test bullets, as shown in Figure 3 below. It shows that individual characteristics present on bullet do not change after its passage through thin iron sheets of thickness upto $1.5 \mathrm{~mm}$. Thus, bullets which had passed through metallic sheets of various thicknesses upto $1.5 \mathrm{~mm}$ encountered in crimes committed by firearms can be linked with the suspected firearm on a thorough and careful examination.

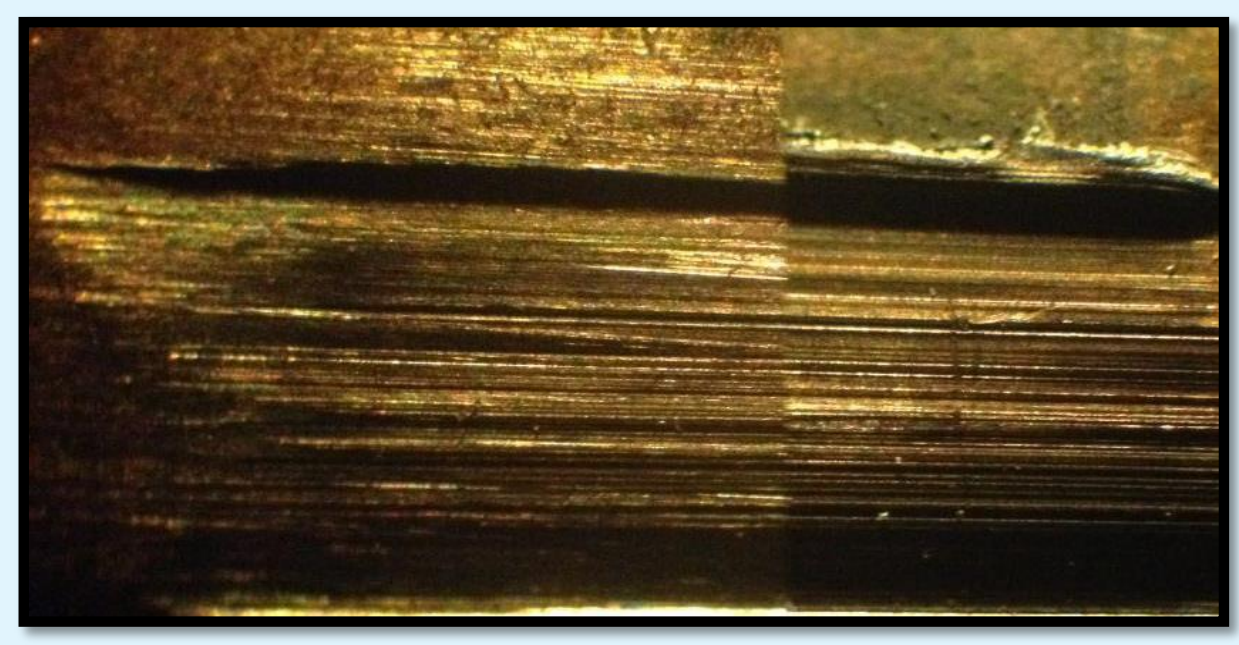

Figure 3: Showing matching of striations on test bullet with that on bullet fired through sheet of gauge number 26. 


\section{International Journal of Forensic Sciences}

When the bullet strikes the sheet, it delivers its energy to the sheet, the sheet moves in the lateral direction and does not make contact with the parallel (cylindrical) portion of the bullet. After passage of the bullet, the metal of sheet returns to its original position because of elasticity of the metal.

It has been mentioned earlier that when the bullet was fired in the sheet of gauge $14(=2 \mathrm{~mm})$, the jacket along with some lead got separated, it moved towards the shooter and lead core passed through the sheet. The jacket that moved backwards was found in folded condition upto half of its length. The rifling striations were found in very small region and when viewed through comparison microscope these marks were found to be matching with those on test bullets. Figure 4 shows matching of striations on the separated jacket of the bullet that was fired in the sheet of gauge14 with striations on test bullets.

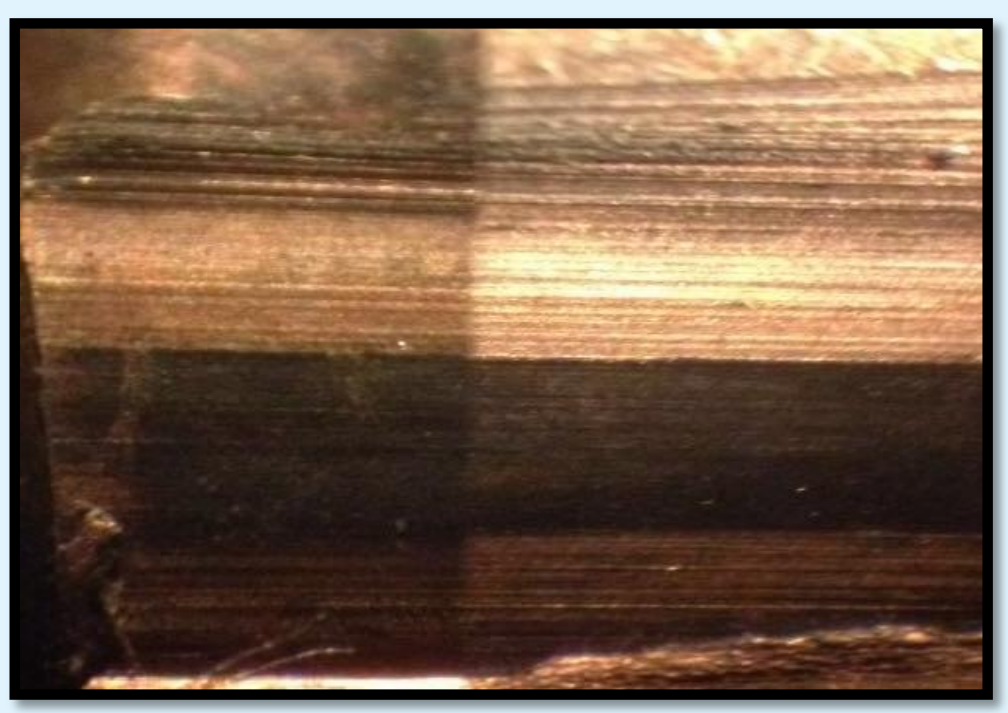

Figure 4: Showing matching of striations on test bullet with those on jacket of bullet fired in sheet of gauge 14 .

The lead core which had passed through the sheet of gauge number14 also bore striations all around its curved surface. These striations are probably caused by irregularities present in the hole margins in the sheet.

\section{Lethality of Bullet after Passage through Iron Sheets}

According to literature on wound ballistics, the lethality of a bullet is measured in terms of its energy density, $E / A$, where ' $E$ ' is the energy of the bullet and ' $A$ ' is the area presented by bullet to human body at the time of impact on body. The threshold value of $E / A$ for penetration of bullet inside human body is given by $(E /$ $A)_{\text {Threshold }}=79.4 \mathrm{ft} . \mathrm{lb} / \mathrm{in}^{2}$.

After entering the human body, the bullet keeps on penetrating till its ' $E / A$ ' value reduces to $79.4 \mathrm{ft} . \mathrm{lb} / \mathrm{in}^{2}$. As mentioned above, the average instrumental velocity of $9 \mathrm{~mm}$ bullet at a distance of 2.3meters from muzzle is1008 $\mathrm{ft} / \mathrm{sec}$.
The energy ( $E$ ) of bullet corresponding to instrumental velocity of $1008 \mathrm{ft} / \mathrm{sec}$ is

$E=\frac{1}{2} m v^{2}$, where $v$ is the velocity of bullet and $m$ is the mass of bullet.

Corresponding to $v=1008 \mathrm{ft} / \mathrm{sec}$,

$$
E=\frac{1}{2} \times \frac{7.49}{454} \times \frac{(1008)^{2}}{32}=261.92 \mathrm{ft} \mathrm{lb}
$$

For perpendicular hit, area ' $A$ ' presented by bullet to body is given by,

$$
\begin{gathered}
A=\pi r^{2} \\
A=3.14 \times\left(\frac{9}{25.4 \times 2}\right)^{2} \\
A=0.0985 \mathrm{in}^{2}
\end{gathered}
$$

Now, $E / A$ value of the bullet is given by,

$$
\frac{E}{A}=\frac{261.92}{0.0985}=2659 \mathrm{ft} \mathrm{lb} / \mathrm{sq} \text {. inch }
$$

When firings were conducted, the average velocities of bullets after their passage through sheets of various thicknesses were determined and are given in the following Table 5. This table also gives the values of ' $E$ ' 


\section{International Journal of Forensic Sciences}

and ' $E / A$ '. The remaining velocities of bullets after passing through sheets of various thicknesses are given as

average of 8 measurements.

\begin{tabular}{|c|c|c|c|c|c|c|}
\hline S.No. & $\begin{array}{c}\text { Gauge Number } \\
\text { of Sheet }\end{array}$ & $\begin{array}{l}\text { Thickness of } \\
\text { Iron sheet (in } \\
\text { mm) }\end{array}$ & $\begin{array}{l}\text { Remaining Velocity } \\
\text { of bullet after } \\
\text { passing through the } \\
\left.\text { sheet }\left(\mathrm{V}_{1}\right) \text { (in } \mathrm{ft} / \mathrm{sec}\right)\end{array}$ & $\begin{array}{c}\text { Loss in velocity } \\
\text { by bullet after } \\
\text { passing through } \\
\text { the sheet }(1008 \text { - } \\
\left.V_{1}\right)(\text { in } f t / s e c)\end{array}$ & $\begin{array}{l}\text { Value of } E \\
\text { corresponding to } \\
\text { the remaining } \\
\text { velocity (in } f t l b \text { ) }\end{array}$ & $\begin{array}{c}\text { Value of E/A (in } \\
\left.\quad f t l b / i n^{2}\right)\end{array}$ \\
\hline 1 & 30 & 0.29 & 1006.6 & 1.73 & 261.192 & 2651.695 \\
\hline 2 & 28 & 0.38 & 942.246 & 66.084 & 228.8625 & 2323.477 \\
\hline 3 & 26 & 0.55 & 971.87 & 36.46 & 243.4795 & 2471.873 \\
\hline 4 & 24 & 0.7 & 1062.78 & -54.45 & 291.1607 & 2955.946 \\
\hline 5 & 22 & 0.8 & 819.43 & 188.9 & 173.0891 & 1757.25 \\
\hline 6 & 20 & 1.05 & 835.61 & 172.72 & 179.992 & 1827.33 \\
\hline 7 & 18 & 1.25 & 779.62 & 228.71 & 156.6794 & 1590.654 \\
\hline 8 & 16 & 1.5 & 838.64 & 169.69 & 181.2997 & 1840.606 \\
\hline 9 & 14 & 2 & 533.29 & 475.04 & 73.31163 & 744.2805 \\
\hline
\end{tabular}

Table 5: Showing the values of energy density (E/A) of bullets after their passage through sheets of different thicknesses.

Because of round-to-round variations of velocities, average value of $1062 \mathrm{ft} / \mathrm{sec}$ in the case of firings through sheet of gauge number 24 was obtained which is higher than the instrumental velocity of 1008 $\mathrm{ft} / \mathrm{sec}$.

From the above Table 5, it can be seen that as the bullet passes through sheets of various gauges, its velocity gets reduced. However, the remaining velocity of the bullet still remains quite high and the values of $E / A$ of the bullet are much higher than the threshold value of $79.4 \mathrm{ft} l \mathrm{lb} / \mathrm{in}^{2}$, required for penetration in human body. This implies that even after passing through sheets of different thicknesses varying from $0.29 \mathrm{~mm}$ to $2.0 \mathrm{~mm}$, the bullet remains lethal. When the thickness of sheet becomes more than $1.5 \mathrm{~mm}$ or so, the firings become dangerous to the shooter as well. The velocity of lead core which passed through sheet of gauge 14 is more than 500 $\mathrm{ft} / \mathrm{sec}$ which is again a very high value and also, the corresponding value of $E / A$ is more than the threshold value for penetration in human body.

This study shows that the bullets after passing through iron sheets of gauge number 20, which is the gauge commonly, used in cars, buses etc., is still lethal when fired from outside the vehicle from a close range. The experiments have shown that fragments of lead core after passing through sheet of gauge 14 had penetrated the stack of cardboards placed at the front of bullet recovery box upto $7-8 \mathrm{~mm}$. This indicates that these fragments can penetrate human body also.
VII. Determination of Type of Bullet that Had Passed Through the Sheet

When a bullet made an impact or passed through the sheet, there is an exchange of material between the projectile and iron sheet. In our experiments, copper could be detected on the iron sheet on the periphery of the hole, inside the hole, and on the inside of rear petals.

For detection of copper, filter paper moistened with liquid ammonia was pressed around the gun-shot hole, dried and treated with solution containing $0.1 \mathrm{gm} \mathrm{o-}$ Tolidine and $0.5 \mathrm{gm}$ Ammonium Thiocyanate mixed in $5 \mathrm{ml}$ Acetone. The appearance of blue colour indicated the presence of copper $[2,4]$.

On the holes formed in sheets with gauge numbers 30 to 14 , copper was tested to be positive. In case of holes in sheets with gauge number 18,16 and 14 , lead was also found to be present around the holes. The reason being that these sheets are thick, the jacket of bullet got cracked or separated from the lead core while bullet's passage through these thick sheets, and lead comes in contact with iron. Lead was detected by the usual Sodium Rhodizonatesolution.

The presence of copper could also be detected on plugs.

\section{Loss in Weight of Bullet}

The average initial weight of $9 \mathrm{~mm}$ bullet $=7.490 \mathrm{gm}$.

In our experiments, when $9 \mathrm{~mm}$ bullets were fired through iron sheets of different gauges, the losses in weight suffered by bullets are given in the following Table 6 and are plotted in Graph 5. 


\section{International Journal of Forensic Sciences}

\begin{tabular}{|c|c|c|c|c|}
\hline S. No & $\begin{array}{c}\text { Gauge Number of } \\
\text { Iron Sheet }\end{array}$ & $\begin{array}{c}\text { Thickness of Iron } \\
\text { sheet } \\
\text { (in mm) }\end{array}$ & $\begin{array}{c}\text { Average Weight of bullet after } \\
\text { passing through the sheet } \\
\text { (in gm) }\end{array}$ & $\begin{array}{c}\text { Weightloss by the bullet after } \\
\text { passing through the sheet } \\
\text { (in gm) }\end{array}$ \\
\hline $\mathbf{1 .}$ & 30 & 0.29 & 7.451 & 0.039 \\
\hline $\mathbf{2 .}$ & 28 & 0.38 & 7.469 & 0.021 \\
\hline $\mathbf{3 .}$ & 26 & 0.55 & 7.448 & 0.042 \\
\hline $\mathbf{4 .}$ & 24 & 0.7 & 7.454 & 0.036 \\
\hline $\mathbf{5 .}$ & 22 & 0.8 & 7.47 & 0.02 \\
\hline $\mathbf{6 .}$ & 20 & 1.05 & 7.477 & 0.013 \\
\hline $\mathbf{7 .}$ & 18 & 1.25 & 7.462 & 0.028 \\
\hline $\mathbf{8 .}$ & 16 & 1.5 & 7.421 & 0.069 \\
\hline $\mathbf{9 .}$ & 14 & 2.0 & 4.752 & 2.738 \\
\hline
\end{tabular}

Table 6: Showing loss in weight of bullets after their passage through iron sheets of different thicknesses.

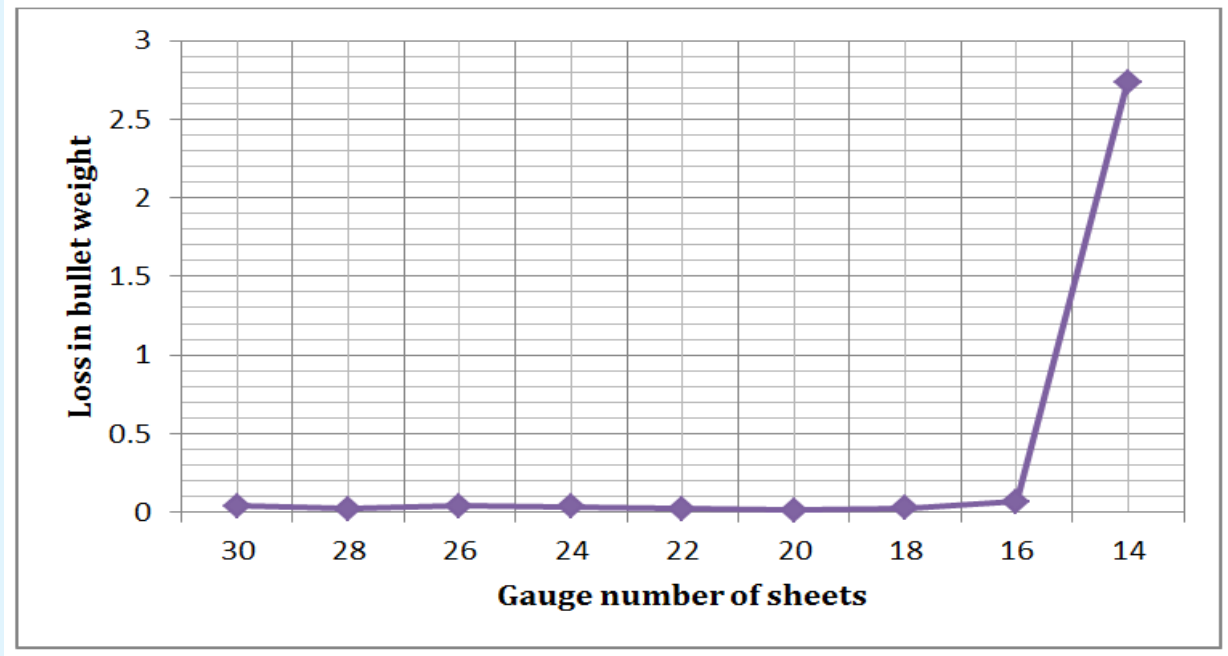

Graph 5: Showing loss in weight of bullets after their passage through iron sheets of different thicknesses.

From this table and graph, it is seen that when the bullet passes through iron sheets of gauge numbers 30 to 18 , it does not suffer any appreciable weight loss. This implies that the resistance offered by sheets to the passage of bullets is negligible, and the bullet is able to defeat these iron sheets. This also shows that when the bullet passes through these sheets, the metal of the sheet moves laterally on taking energy from the bullet, and does not come in contact with the bullet and the bullet passes through the sheets without losing much weight.

When the $9 \mathrm{~mm}$ bullet passed through sheet of gauge $16(1.5 \mathrm{~mm}$ thick), the thickness of sheet presents considerable resistance to its passage. Here, the weightloss was $0.069 \mathrm{gm}$.
When the bullets passed through sheet of 14 gauge ( $2.00 \mathrm{~mm}$ thick), the resistance offered was such that the firings were really dangerous to the shooter. The jacket and some parts of the lead core got removed by the sheet. This fragment flew backwards towards the shooter and proved dangerous to the shooter. The remaining part of the lead core passed through the sheet making hole of diameter $10.68 \mathrm{~mm}$. Weight loss by the bullet is $2.738 \mathrm{gm}$. In other words, a piece of copper jacket along with some part of lead weighing $2.738 \mathrm{gm}$ altogether flew towards the shooter.

In shootings, $9 \mathrm{~mm}$ bullets are many times fired by Police because it is prohibited ammunition. These bullets may pass through iron sheets of various gauges. These bullets may easily pass through objects fitted with iron 


\section{International Journal of Forensic Sciences}

sheets of gauge upto 18. However, when the sheet thickness increases, the bullet may fragment and these fragments may fly towards the shooter and may prove dangerous to him.

\section{Stippling around the Wound of Entrance}

It was observed that when $9 \mathrm{~mm}$ pistol bullets passed through iron sheets of gauge 30 and 28, small iron chips got cut from the sheet and flew in the direction of bullet. These particles got embedded in bullet recovery box around the main hole caused by bullet. These chips, embedded around the gun-shot hole were visible to the naked eye. It is concluded that when a bullet which had passed through an iron sheet may strike a victim sitting next to the sheet and the gun-shot hole may be surrounded by holes caused by such small chips. This is called 'Stippling'. This pattern caused by small iron chips may look like tattooing around the gun-shot hole. A defence counsel may try to confuse it as a close range shot by some person other than the accused. In order to avoid such confusion, tests for tattooing and iron should be conducted to prove that this stippling has been caused by the penetration of iron particles and is not tattooing.

\section{Conclusion}

In this paper, the authors have reported the results of orthogonal firings of $9 \mathrm{~mm}$ jacketed bullets through iron sheets of different thicknesses. The muzzle velocities of the bullets were approximately $1000 \mathrm{ft} / \mathrm{sec}$. The thicknesses of sheets varied from $0.29 \mathrm{~mm}$ to $2.00 \mathrm{~mm}$. From these firings, following conclusions are drawn:

a) When the bullet passes through sheets of various thicknesses, the bullet loses its energy. Stresses are developed both in bullet and sheet. Some of the energy of the bullet is used up in deformation of its nose, some energy is used up in bending the sheet in the direction of motion of the bullet, formation of backward petalling, cutting of some pieces of iron, plug formation and lateral movement of metal surrounding the hole.

b) When the bullet makes impact on iron sheet, the stresses are developed in the bullet. In the case of thin sheets, say gauge number 30 (thickness $=0.29 \mathrm{~mm}$ ), these developed stresses in the bullet are less than its elastic limit. Nose of the bullet is not appreciably deformed. As the thickness of sheet increases, say in sheets of gauge number 28,26,24,22, the stresses developed are more than the elastic limit of bullet, but less than the yield point, the stresses produced deforms the bullet nose. In case of sheet number 20 , the jacket on lead core starts splitting. In case of gauge number
16 , the nose mushrooms. In sheet of gauge number 14 (thickness $=2.00 \mathrm{~mm}$ ), the stresses developed reach the breaking point of bullet. The jacket gets separated and only the core passes through the sheet. This core may form a disc. Here, the jacket may move towards the shooter and such firings may prove dangerous for him.

c) Sheet bends in the direction of motion of bullet causing backward petalling. Also, there is formation of plug. This plug may remain attached to the nose of the bullet and may enter human body along with the bullet. This plug may get separated from the bullet, but may enter the body and cause a separate entrance wound. Or, the plug may fall on the ground and the bullet only may produce wound of entrance.

d) The metal of sheet surrounding the hole moves in lateral direction. The stresses which cause the metal to move in lateral direction depend upon sheet thickness. This fact together with bullet nose deformation helps in determining whether the diameter of hole will be smaller or larger than the calibre of bullet. In thin sheets, the stresses are less than the elastic limit of the sheet and the nose of the bullet only flattens slightly and does not deform much which shows the diameter of bullet hole is smaller than the calibre of the bullet. As the thickness increases, more energy is used up in lateral movement of metal around the hole and also, nose of the bullet gets deformed and thus, the diameter of the hole is approximately equal to bullet calibre. But, when we move from sheet of gauge number 20 (1.05mm thick) to $14(2.0 \mathrm{~mm}$ thick), the bullet nose expands and the stresses which help in lateral movement of metal around the hole are large and it results in increase in the diameter of bullet hole. Hence, the hole is of larger diameter than the calibre of the bullet.

e) Because of lateral movement of metal around the bullet hole, bullet may not come in contact with metal of hole. So, the striations on bullet left by the individual characteristics of firearm are not affected when the bullet passes through the sheet. So, the bullet can be linked with the suspected firearm. Even in the case of sheet of gauge number 14, when the jacket gets separated form core, the jacket may bear identifiable striations.

f) It was found that $9 \mathrm{~mm}$ bullets are lethal even after their passage through these iron sheets.

g) Small iron particles are also produced and move in the direction of motion of the bullet. These iron particles may cause contusions around gun-shot hole in body. This pattern may be confused for tattooing caused by 


\section{International Journal of Forensic Sciences}

propellant particles. To avoid this confusion, necessary tests should be performed.

h) When the $9 \mathrm{~mm}$ bullets passed through these sheets, except in sheet of gauge number 14, bullets did not lose appreciable weight, confirming the fact that as soon as the bullet makes impact on the sheet, there is lateral movement of the metal surrounding the bullet hole, and bullet does not come in much contact with metal.

\section{Acknowledgements}

The authors are extremely grateful to Director, Lok Nayak Jayaprakash Narayan National Institute of Criminology and Forensic Science, Ministry of Home Affairs, Government of India, New Delhi and to Director, Central Forensic Science Laboratory, Ministry of Home Affairs, Government of India, Hyderabad for their constant encouragement.

\section{References}

1. Carlucci DE, Jacobson SS, (2008) Ballistics: Theory and Design of Guns and Ammunition. CRC Press, Taylor \& Francis Group, Florida, USA, pp: 315.

2. Sharma BR (2011) Firearms \& Criminal Investigation and Trials. $4^{\text {th }}$ (Edn.), Universal Law Publishing Co. Pvt. Ltd., New Delhi.

3. Mathur DS (1949) Elements of Properties of Matter. Published by Shyamlal Charitable Trust, New Delhi, 2N5.

4. Feigl F, Anger V (1972) Spot Tests in Inorganic Analysis. 6th Edition, Third print 2003, Elsevier, The Netherland, pp: 209-210.

5. Farrar CL, Leeming DW (1983) Military Ballistics: A Basic Manual". Brassey's Publishers Limited, Oxford, England, pp: 143. 